\title{
Gender Difference and Its Effect on Agricultural Productivity: The Case of Yubdo District in Ethiopia
}

\author{
Bacha Gebissa \\ Department of Agricultural Economics, Wollega University, Shambu, Ethiopia \\ Zekarias Shumeta \\ Department of Agricultural Economics, Jimma University, Jimma, Ethiopia \\ Guta Regassa \\ Department of Rural Development, Jimma University, Jimma, Ethiopia
}

\begin{abstract}
This research is financed Wollega University, Ethiopia
Abstract

Rural men and women have different access to productive resources which may hinder women's productivity and reduce their contributions to agriculture. This research was conducted to analyze difference in agricultural productivity between male and female headed households in Yubdo district of West Wollega Zone, Oromia National Regional State. The study used cross-sectional data that is collected from a total of 150 sampled respondents. The data were analyzed by descriptive statistics and econometric model. Results of the study showed that male headed households own more of productive resources such as land, livestock, labour and other agricultural inputs as compared to female headed households. Additionally, Cobb-Douglas production function was used to estimate the productivity difference in agriculture between male and female headed households. The result indicated that farm land, inorganic fertilizer, labour, number of oxen and number of extension contact were statistically significant in influencing the productivity of male headed households while farm land, inorganic fertilizer, labour, herbicide and improved were significant variables affecting the productivity of female headed households. The comparison of the marginal value product with the factor cost showed that both male and female headed households could increase productivity using more labour and farm land. The agricultural productivity difference between male and female headed households was about $70.84 \%$ in the study area. On the other hand, if female headed households had equal access to the inputs as male headed households, gross value of the output would be higher by $17.6 \%$ for female headed households. This may suggest that female headed households would have been more productive than male headed households if they had equal access to inputs as male headed households. Thus accessing female headed households to inputs that increase the productivity of land, labour utilization, usage of herbicide; and introducing technologies that reduce the time and energy of women is essential to improve the agricultural productivity of women and the society as a whole.
\end{abstract}

Keywords: Cobb-Douglas, Decomposition Model, Ethiopia, Yubdo

DOI: $10.7176 / \mathrm{JESD} / 10-19-06$

Publication date:October $31^{\text {st }} 2019$

\section{INTRODUCTION}

Most of the smallholder farmers in Sub-Saharan African countries' agricultural productivity are generally low (Olakojo, 2017). The low level of agricultural productivity is mostly for female farmers compared to their male counterparts'. Studies have persistently identified a gender gap in agricultural productivity of 20 to 30 percentage points in disadvantage of women as an important obstacle for the development of the agricultural sector. Numbers of these studies indicate that once differences in access to productive resources and individual characteristics are taken into account, estimates of the gender productivity gap become insignificant. Henceforth, the evidence speaks of a difference in productivity that arises mainly from differential access to resources and differential farmers' characteristics by gender (Kilic et al., 2015).

In general rural women in the developing world and throughout Ethiopia in particular make critical contributions to household agricultural production and productivity consequently to household and national food security. However, it is often mentioned that most of the household decisions related to production, processing and marketing are dominated by male members of the households. Women not only need access to productive resources but also need to use those resources efficiently by making necessary decisions in farming activities. Because of socially constructed roles, various factors may affect women's level of involvement in such decision making (Sinidu, 2017).

Yubdo district is one of the highly populated areas in West Wollega Zone of Ethiopia where population density is about 217 persons per $\mathrm{Km}^{2}$ (CSA, 2018). As the result, farm size is so small to produce sufficient food to the population and the number of female headed households is also increasing from time to time because of death of husband, divorce problem and migration of males to other areas in search of better employment leaving 
behind their wives and children. Thus, females would take over the position of their husband in addition to their routine household management. Therefore, it is essential to study the productivity of female headed households in agricultural sector as compared with their male counterparts in the area for intervention via program targeting.

\section{MATERIALS AND METHODS}

\subsection{Description of the Study Area}

Yubdo district is one of the twenty three districts found in West Wollega Zone of Oromia National Regional State (figure1). It is located at a distance of $548 \mathrm{Km}$ from Finfinne, the capital city of the country to the west. The capital town of the zone is Gimbi which is $110 \mathrm{Km}$ from the district. The district is bounded by Aira Guliso in the North, Lalo kile in the West, Nole Kaba in the South and Ganji in the East.

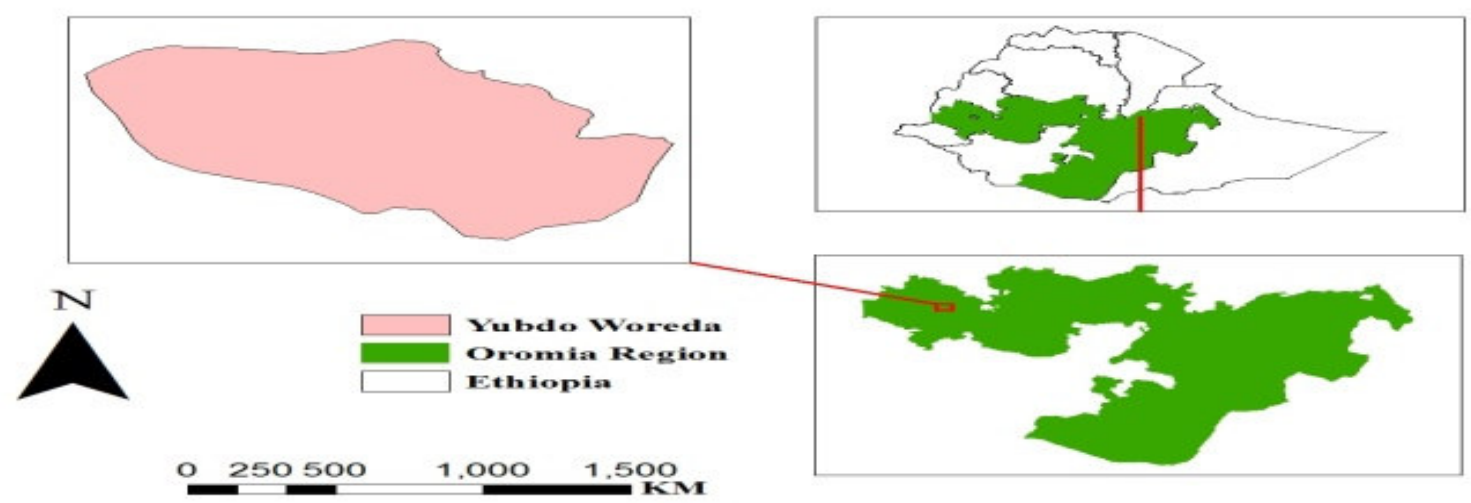

Figure 1. Map of study area Source: Ethio- GIS (2018)

\subsection{Type, Source and Methods of Data Collection}

Both qualitative and quantitative data were collected from primary and secondary sources.

The qualitative data were collected through focus group discussion and participatory observation. The quantitative data were gathered by conducting a formal household survey using structured questionnaire.

\subsubsection{Sampling Method and Sample Size Determination}

The study employed probability sampling procedure to draw a representative sample. Two stage sampling procedure was used to select sample households. In the first stage, six kebeles were selected randomly from 20 Kebeles found in the district. In the second stage from these 6 Kebeles 75 male and 75 female headed households are randomly selected. Probability Proportional to sample size was employed to select the total of sampled households' farmers. Hence, a total of 150 households were selected (table 1). The sample size was determined using the formula given by Yamane (1967: 886) as follow:

$n=\frac{N}{1+N\left(e^{2}\right)}$

Where:

$n$-Represents sample size

$N$-Represents total number Male headed and Female Headed

$e$-Represents the desired level of precision (taking $8 \%$ )

Table 1. Distribution of sample households by Kebeles and sex of household head

\begin{tabular}{lcccccc}
\hline \multirow{2}{*}{ Kebele } & \multicolumn{2}{c}{ Total number of MHH and FHH in the } & \multicolumn{3}{c}{ Sample } \\
& \multicolumn{3}{c}{ selected kebeles } & \multicolumn{1}{c}{} \\
\cline { 2 - 7 } Bikiltu Aira & Male Headed & Female Headed & Total & Male Headed & Female Headed & Total \\
\cline { 2 - 7 } Muco Aira & 417 & 74 & 491 & 11 & 9 & 20 \\
Worra Gutu & 452 & 125 & 577 & 10 & 14 & 24 \\
Boti Aira & 515 & 93 & 608 & 13 & 12 & 25 \\
Jemalogi Aira & 634 & 123 & 757 & 17 & 14 & 31 \\
Jarso Boloso & 485 & 82 & 567 & 10 & 13 & 23 \\
\hline Total & 524 & 123 & 647 & 14 & 13 & 27 \\
\hline \hline
\end{tabular}

Source: Administration Office Baseline Survey and Survey Sampling (2018) 


\subsection{Methods of Data Analysis}

Descriptive and inferential statistics as well as econometric model were used to analyze the data using SPSS vers ion 20.

\subsubsection{Descriptive and inferential statistics}

The study used descriptive statistics such as frequency, percentage, means, standard division, minimum and maximum; and inferential statistics such as t-test and chi-square.

\subsubsection{Econometric analysis}

Cobb-Douglas production function was used to examine the agricultural productivity differences between the male and female headed households. According to Gujarati (2004), the generalized form of the Cobb-Douglas production function can be specified as:

$$
\mathrm{Y}=\mathrm{AX}_{1}^{\mathrm{B} 1} \mathrm{X}_{2}^{\mathrm{B} 2} \mathrm{X}_{3}^{\mathrm{B} 3} \ldots \mathrm{X}_{\mathrm{n}}^{\mathrm{Bn}} \mathrm{e}^{\mathrm{Ui}}
$$

Where, $\mathrm{Y}$ is gross value of farm outputs in birr per ha, Xi's are explanatory variables A is efficiency parameter and represents the level/state of technology and $U_{i}$ is disturbance term.

The estimation technique employed in this study was Ordinarily Least Square (OLS). Since the Cobb-Douglas production function is a power function, it is impossible to directly use the Ordinary Least Square (OLS) method. Therefore, logarithmic transformation is making to obtain its linear form and to estimate the parameters. In this study, the natural logarithm was employed.

To examine whether the production functions of male headed households (MHH) and female headed households $(\mathrm{FHH})$ are different from each other, equation 3 was estimated separately for $\mathrm{MHH}$ and $\mathrm{FHH}$. Productions function for $\mathrm{MHH}$ :

$$
\ln Y_{M}=\ln A_{M}+B_{1 M} \ln X_{1 M}+B_{2 M} \ln X_{2 M}+B_{3 M} \ln X_{3 M}+. .+B_{12 M} \ln X_{12 M}+U_{M} \ldots
$$

Productions function for $\mathrm{FHH}$ :

$$
\ln Y_{\mathrm{f}}=\ln \mathrm{A}_{\mathrm{f}}+\mathrm{B}_{1 \mathrm{f}} \ln \mathrm{X}_{1 \mathrm{f}}+\mathrm{B}_{2 \mathrm{f}} \ln \mathrm{X}_{2 \mathrm{f}}+\mathrm{B}_{3 \mathrm{f}} \ln \mathrm{X}_{3 \mathrm{f}}+\ldots \ldots+\mathrm{B}_{12 \mathrm{f}} \ln \mathrm{X}_{12 \mathrm{f}}+\mathrm{U}_{\mathrm{f}} \ldots \ldots \ldots \ldots \text {. }
$$

Production function using pooled data:

$$
\ln Y_{p}=\ln A_{p}+B_{1 p} \ln X_{1 p}+B_{2 f} \ln X_{2 p}+B_{3 p} \ln X_{3 p}+\ldots \ldots .+B_{12 p} \ln X_{12 p}+U_{p} \ldots(6)
$$

Where, $\mathrm{m}=$ MHH, $\mathrm{f}=\mathrm{FHH}, \quad \mathrm{p}=$ Pooled data set and $\mathrm{B}_{\mathrm{im}}, \mathrm{B}_{\mathrm{if}}$ and $\mathrm{B}_{\mathrm{ip}}(\mathrm{i}=1,2 \ldots 7)$ are output elasticities of $\mathrm{i}^{\text {th }}$ input under $\mathrm{MHH}, \mathrm{FHH}$ and pooled data sets, respectively.

Finally, Oaxaca-Blinder decomposition model of the productivity differential between male and female farmers was used to decompose the productivity difference (Oaxaca, 1973). Although this approach is to decompose the wage gap, it can also be applied to decompose productivity

difference between, say, men and women farmers (Shambel, 2013; Tadele and Mahendran, 2015).The decomposition model adopted was presented as follows:

$$
\begin{aligned}
& \ln \left(\frac{Y_{m}}{Y_{f}}\right)=\left\lceil\left(B_{i m}-B_{i f}\right) \ln X_{i f}\right\rceil+ \\
& {\left[B_{1 f} \ln \left(\frac{X_{i m}}{X_{i f}}\right)\right] \ldots \ldots \ldots \ldots \ldots \ldots \ldots \ldots \ldots \ldots \ldots \ldots \ldots \ldots \ldots \ldots \ldots}
\end{aligned}
$$

Where:-

$Y_{m}$ and $Y_{f}$ represent mean output (Geometric mean) of males and females respectively

$X_{\text {im }}$ and $X_{\text {if }}$ are geometric mean levels of inputs of male and female

$B_{\text {im }}$ and $B_{\text {if }}$ are estimate of output elasticities of male and female headed households as

defined earlier.

The model decomposes the overall average male-female output gap into a portion emanating from differences in the technical efficiency and the portion attributable to differences in input endowments. In other words, the first bracketed expression on the right hand side is a measure of change in output due to shift in output elasticities of the production functions. The second bracketed term is a measure of difference in output due to difference in volume of input use per hectare.

\section{RESULT AND DISCUSSION}

\subsection{Results of Descriptive statistics}

\subsubsection{Land use pattern and use of fertilizer, improved seed and herbicides}

This study found that there was land holding difference in the study area between the two groups. The result showed that the total land holding of the sample households was 334.82 ha where the average per household was $2.23 \mathrm{ha}$. The minimum and maximum land holding for male headed household was 1 and 6 ha respectively, while it was 0.5 and 5 ha respectively for the corresponding female headed households. The average cultivable landholding was slightly different from the total showing all the land owned were not used for production of agricultural produces. Male headed households had about 2.80 ha of cultivable land while that of female headed households was 2.05 ha, the difference being significant at $10 \%$ probability level $(\mathrm{t}=1.71)$.

Comparing the two groups of the households, male headed households were better in using agricultural input 
than the female headed households. The average fertilizer (NPS and UREA), improved seed and herbicides used by male headed households were $85.7,24.94,14.43$ and $3.09 \mathrm{~kg}$ respectively where as the result found for the female headed households were $62.72,17.83,11.37$ and $3.05 \mathrm{~kg}$ respectively. The deferential results between the two groups in using fertilizer (NPS and UREA) and improved seed were significant at 10 and 1\% probability level respectively.

\subsubsection{Livestock Holding}

The mean livestock holdings for the sample households were 3.84 TLU, of which the average for the male and female headed households were 3.87 and 3.80 TLU respectively. The result exhibited substantial difference in livestock ownership between the two groups of households indicating that male headed households are relatively wealthier than the female headed households as livestock is a measure of wealth and source of income in the study area.

\subsubsection{Sources of farm income}

Rural people derive income from multiple sources both from within and outside agriculture. They have commonly more than one source of income as they usually participate in both on farm and off farm activities. Sales of crops, livestock and their by products, and off-farm activities are the major cash income sources for the households in the study area. The mean cash income from different crops which constitutes the highest proportion was about 27,702.28 birr for $\mathrm{MHH}$ and 21,261.4 birr for $\mathrm{FHH}$, the difference is significant at 1\% probability level $(\mathrm{t}=2.83)$.

\subsection{Results of Econometric Models}

\subsubsection{Estimation of the production function}

The farmland of a farmer is one of the most important variables affecting the level of farmers' gross value of output per ha. It has a significant and positive impact on productivity of agriculture in both MHH and FHH. Other factors being constant, a $1 \%$ increase in the area under the major crops increases gross value of farm output by $0.418 \%$ and $0.275 \%$ for male and female headed households, respectively. In other words, these figures indicate that farmland contributed about $41.8 \%$ and $27.5 \%$ to the output of the total inputs for $\mathrm{MHH}$ and $\mathrm{FHH}$, respectively. Table 2. Coefficient of cob-Douglas production function

\begin{tabular}{|c|c|c|c|c|c|c|c|}
\hline \multirow[b]{2}{*}{ Variables } & \multirow[b]{2}{*}{ Unit } & \multicolumn{2}{|c|}{ MHH (75) } & \multicolumn{2}{|c|}{ FHH(75) } & \multicolumn{2}{|c|}{ Pooled (150) } \\
\hline & & Coefficient & $\mathrm{P}>\mathrm{t}$ & Coefficient & $\mathrm{P}>\mathrm{t}$ & Coefficient & $\mathrm{P}>\mathrm{t}$ \\
\hline Constant & & 10.075 & 0.000 & 9.524 & 0.000 & 9.75 & 0.000 \\
\hline SILIHO & TLU & 0.056 & 0.407 & -0.006 & 0.928 & $0.088 *$ & 0.076 \\
\hline LSIZE & На & $0.418 * * *$ & 0.000 & $0.275 * * *$ & 0.008 & $0.376 * * *$ & 0.000 \\
\hline EDU & Years & 0.003 & 0.783 & -0.001 & 0.922 & $0.014^{*}$ & 0.065 \\
\hline INFERT & $\mathrm{Kg} / \mathrm{ha}$ & $0.167 * *$ & 0.024 & $0.332 * *$ & 0.012 & $0.316 * * *$ & 0.000 \\
\hline HERB & Litre/ha & 0.017 & 0.645 & $0.199 * * *$ & 0.008 & $0.096 * *$ & 0.045 \\
\hline LBOUR & Man-days & $0.009 * *$ & 0.043 & $0.022 *$ & 0.072 & $0.012 * *$ & 0.022 \\
\hline ACCREDIT & Birr & -0.006 & 0.071 & 0.001 & 0.969 & -0.004 & 0.267 \\
\hline IMPSEED & $\mathrm{Kg} / \mathrm{ha}$ & 0.057 & 0.361 & $-0.166^{* * *}$ & 0.008 & $-0.064 *$ & 0.074 \\
\hline NEXCONT & No of contact & $-0.028 * *$ & 0.021 & -0.015 & 0.259 & -0.012 & 0.196 \\
\hline FAEXP & Years & -0.064 & 0.564 & -0.042 & 0.803 & $-0.174 *$ & 0.079 \\
\hline OXEN & Number & $0.200 * *$ & 0.034 & 0.002 & 0.991 & $0.213 * * *$ & 0.008 \\
\hline NFINCME & Birr & 0.005 & 0.195 & 0.001 & 0.852 & 0.005 & 0.245 \\
\hline$\overline{\mathrm{R}^{2}}$ & & $70.09 \%$ & & $44.86 \%$ & & $65.29 \%$ & \\
\hline Adjusted $\mathrm{R}^{2}$ & & $64.30 \%$ & & $34.19 \%$ & & $62.24 \%$ & \\
\hline F-Value & & 12.10 & 0.000 & 4.20 & 0.0001 & 21.47 & 0.000 \\
\hline
\end{tabular}

$\mathrm{NB}: * * *, * *$ and $*$ significant at $1 \%, 5 \%$ and $10 \%$ probability level

Source: Own survery (2018)

The elasticity coefficient of inorganic fertilizer for male and female headed households was important variables that affect the productivity of agriculture at 5\% probability level for male headed and female headed households. Increasing inorganic fertilizer by $1 \%$ in male headed and female headed household increase productivity by $0.167 \%$ and $0.332 \%$ respectively. In other words these figures indicate that inorganic fertilizer contributed about $16.7 \%$ and $33.2 \%$ to the output of the total inputs for $\mathrm{MHH}$ and $\mathrm{FHH}$, respectively.

Labour contributed positively and significantly to the agricultural production and gross value of farm output at $5 \%$ and $10 \%$ level of probability for male headed and female headed household respectively. The result of the survey showed that increasing labour by $1 \%$ increases the gross value of farm output by $0.009 \%$ and $0.022 \%$ for male headed households and female headed households correspondingly. The labour elasticity was relatively higher for female headed households implying labour was more efficiently utilized in farm production in this household. 
Table 3. Decomposition of productivity difference between $\mathrm{MHH}$ and $\mathrm{FHH}$

\begin{tabular}{lcc}
\hline \multirow{2}{*}{ Sources of productivity difference } & \multicolumn{2}{c}{ percentage Contribution } \\
\cline { 2 - 3 } & Due to output elasticities & Due to input endowments \\
\hline \hline Total estimated difference $(70.84 \%)$ & -17.6 & 88.44 \\
\hline Livestock holding & 8.5 & 1 \\
Land used & -1.6 & 67.5 \\
Educational level & -2.7 & 0 \\
Fertilizer used & -68.7 & 17.4 \\
Herbicides used & 83.8 & -4.6 \\
Labour used & -5.6 & 9.8 \\
Amount of credit used & -4.8 & 0.04 \\
Improved seed used on average & -51.3 & -0.69 \\
Number of extension contact & -4.5 & -1.5 \\
Farm experience & -7.2 & 0.5 \\
Number of oxen & 33.7 & -1.1 \\
Non-farm/off farm income & 2.8 & 0.09 \\
\hline \hline
\end{tabular}

Source: Own survey (2018)

Number of oxen for male headed and herbicide for female headed were contributed positively and significantly to the agricultural production and gross value of farm output at $5 \%$ and $1 \%$ level of probability respectively. The result of the survey showed that increasing oxen and herbicide by $1 \%$ increases the gross value of farm output by $0.20 \%$ for male headed and $0.199 \%$ for female headed households. In other words this information indicate that number of oxen contributed about $20 \%$ and amount of herbicide contributed about $19.9 \%$ to the output of the total inputs for $\mathrm{MHH}$ and $\mathrm{FHH}$, respectively.

Improved seed for female headed and extension for male headed contributed negatively and significantly to the agricultural production and gross value of farm output at $1 \%$ and $5 \%$ level of probability for both. The result of the survey showed that increasing improved seed by $1 \%$ decreases the gross value of farm output by $0.166 \%$ for female headed households and $0.028 \%$ for male headed. This is due to the increasing price of improved seed over time for female headed and less contact of DA in the study area for male headed households.

As shown in the above table it can be seen that the total productivity difference in agriculture between the two groups was about $70.84 \%$. However, they have different human capital, endowment and different access to factors and inputs as discussed in the descriptive part. Inputs use differentials accounted for $88.44 \%$. This implies that the productivity could be increased by $88.44 \%$, if the FHH could adjust their inputs to the same level of $\mathrm{MHH}$. On the other hand, the difference in output elasticities was $-17.6 \%$. This indicates that productivity difference as the result of difference in output elasticities is greater for $\mathrm{MHH}$ as compared to that of $\mathrm{FHH}$.

A comprehensive assessment of the contributions made by different inputs in the total productivity gap between male and female headed households reveals that difference in access to land use caused the biggest bound. This further indicates that if FHH could adjust their farm land to the level of MHH, they can increase their productivity by about $70.84 \%$. Hence, increasing the access of FHH to farm land could highly increase their productivity in agriculture in the study area. Descriptive results of this study also show that on average FHH had only 2.05 mean of land size while MHH had about 2.80 mean of land size on average, which was significant at $1 \%$ probability level $(\mathrm{t}=1.71)$. And also inorganic fertilizer, labour, livestock holding, farming experiences, Non- farm income and amount of credit use contributes difference between $\mathrm{MHH}$ and FHH made about 17.4\%, 9.8\%, 1\%, $0.5 \%, 0.09 \%$ and $0.04 \%$ productivity difference in agriculture, respectively (table 3 ).

Most researchers often argued that women's lack of access to resources results in lower productivity or inability to respond to economic incentives [(Shambel, 2013; Tadele and Mahendran, 2015). Looking at the contribution made by the output elasticities or change in factor specific productivity, herbicides used is one of the variables which contribute largely to output elasticities or change in factor specific productivity difference. Which constitutes $83 \%$ to the total output difference followed by fertilizer used and improved seed in which they reduce the diffence in output gap by $68.7 \%$ and $51.3 \%$ respectively. Number of oxen and non-farm/off-farm income contributes output gap between $\mathrm{MHH}$ and $\mathrm{FHH}$ by $33.7 \%$ and $2.8 \%$ correspondingly.

\section{CONCLUSION}

Twelve variables were hypothesized to affect the gross value of farm output per ha. The results of the production function analysis revealed that four variables were positively and statistically significant for MHH such as farmland, inorganic fertilizer, labour and number of Oxen while farmland, inorganic fertilizer, labour and herbicide use were positively and statistically significant for FHH. Improved seed for female headed and number of extension contact for male headed contributed negatively and significantly to the agricultural production and gross value of farm output. 


\section{ACKNOWLEGEMENTS}

At the beginning, I would like to praise the perpetual Father and the Prince of love and peace, the Almighty God, who always let the bulk of unfinished work to be completed at a moment. Next, I am grateful to the invaluable support of my major advisor Dr. Zekarias Shumeta, for his unreserved advice, guidance, and constructive observations starting from the very commencement up to thesis completion.

\section{REFERENCES}

Olakojo, S.A., 2017. Gender gap in agricultural productivity in Nigeria: A commodity level analysis. Economics of Agriculture, 64(2): 415-435.

Kilic,T., Palacios-Lopez, A. and Goldstein, M., 2015. Caught in a productivity trap: a distributional perspective on gender differences in Malawian agriculture. World Development, 70: 416-463.

Sinidu Gashaw, 2017. Determinants of Rural Women Empowerment in East Hararghe Zone, Ethiopia.

CSA (Central Statistical Agency), 2018. Agricultural sample survey: Area and production of crops, main season, Annual Report of Yubdo.

Yamane Taro, 1967.Statistics: An introductory analysis, $2^{\text {nd }}$ Ed., New York: Harper and Row Gujarati, D., 2004. Basic econometrics. The Mc-Graw Hill.

Oaxaca, R., 1973. Male-Female differentials in urban labour markets. International Economic Review, 14(1): 69309.

Tadele Melaku and Dr. A. Mahendran, 2015. Gender difference and its impact on agricultural productivity: The case of Sheko district in bench Maji zone of SNNP, Ethiopia”, International Journal of Current Research, 7(11): 22938-22942. 